ISSN 1983-8484

Licenciado sob uma Licença Creative Commons

\title{
Uma proposta de planejamento estratégico para a reposição de produtos nas lojas de uma rede supermercadista
}

\author{
A proposal for strategic planning for the replacement of \\ products in stores of a supermarket network
}

Cassius Tadeu Scarpin ${ }^{[a]}$, Fernando Yudi Sakaguti ${ }^{[b]}$, Maria Teresinha Arns Steiner ${ }^{[c]}$

[a] Doutorando em Métodos Numéricos em Engenharia pela Universidade Federal do Paraná (UFPR), professor assistente da Universidade Federal do Paraná (UFPR), Curitiba, PR - Brasil, e-mail: cassiusts@gmail.com

[b] Mestre em Métodos Numéricos em Engenharia pela Universidade Federal do Paraná (UFPR), professor assistente da Faculdade de Filosofia, Ciências e Letras de Paranaguá (FIFAPAR), Paranaguá, PR - Brasil, e-mail: feryudi@yahoo.com.br

[c] Doutora em Engenharia de Produção pela Universidade Federal de Santa Catarina (UFSC), professora sênior da Universidade Federal do Paraná (UFPR), Curitiba, PR - Brasil, e-mail: tere@ufpr.br

\section{Resumo}

Neste trabalho apresenta-se uma proposta de planejamento estratégico de reposição de produtos nas lojas de uma rede supermercadista. Utiliza-se, para isso, um método quantitativo para a previsão de séries temporais, as Redes Neurais Artificiais de Bases Radiais (RBF), e, também, é proposto um método qualitativo de interpretação dos resultados de previsão e estabelecimento de limites de estoque para cada produto de cada loja da rede. 0 objetivo com este planejamento estratégico é a redução dos níveis de ruptura dos produtos (falta de produtos nas gôndolas), assim como o não ocasionamento de superestocagem, além do aumento do nível de serviço logístico aos clientes. Os resultados obtidos foram altamente satisfátórios, reduzindo a ruptura do CD-Loja, em média, de 12\% para cerca de $0,7 \%$ nos hipermercados e de $15 \%$ para $1,7 \%$ nos supermercados, gerando assim inúmeras vantagens competitivas para a empresa. A aplicação das RBF's para a previsão mostrou-se eficiente quando utilizada em conjunto com a estratégia de reposição proposta neste trabalho, tornando os processos operacionais efetivos.

Palavras-chave: Reposição de produtos. Redes neurais artificiais de bases radiais. Ruptura. Previsão de séries temporais. Nível de serviço logístico.

\footnotetext{
Abstract

This paper presents a proposal for strategic planning for the replacement of products in stores of a supermarket network. A quantitative method for forecasting time series is used for this, the Artificial Radial Basis Neural Networks (RBFs), and it is also proposed a qualitative method to interpret the forecasting results and establish limits for each product stock for each store in the network. The purpose with this strategic planning is to reduce the levels of out-of-stock products (lack of products on the shelves), as well as not to produce overstocking, in addition to increase the level of logistics service to customers. The results were highly satisfactory reducing the
} 
Distribution Center (DC) to shop out-of-stock levels, in average, from $12 \%$ to about $0.7 \%$ in hypermarkets and from $15 \%$ to about $1.7 \%$ in supermarkets, thereby generating numerous competitive advantages for the company. The use of RBFs for forecasting proved to be efficient when used in conjunction with the replacement strategy proposed in this work, making effective the operational processes.

Keywords: Product replacement. Artificial radial basis neural networks. Out-of-stock. Forecasting time series. Level of logistics services.

\section{Introdução}

O setor supermercadista, um dos mais importantes do varejo nacional, vem passando por grandes transformações. Alguns fatos históricos na economia nacional, como a entrada em vigor do Código de Proteção e Defesa do Consumidor, implantação do plano real e o controle do índice de inflação, aumentaram, ainda mais, a competitividade entre as empresas desse setor. Com este cenário competitivo, torna-se essencial para uma empresa traçar estratégias efetivas e bem definidas para atingir o objetivo de oferecer ao consumidor preços atraentes, grande mix de produtos e qualidade nos serviços prestados (BENETTI et al., 2008). Nesse ambiente, em que a competição obriga a realização da atividade com margens reduzidas, é fundamental que as empresa comerciais atentem para as condições operacionais (ÂNGELO; SIQUEIRA, 2000).

Um dos problemas mais críticos que impedem que esses objetivos sejam atingidos no varejo é a ruptura de produtos nas gôndolas das lojas. A ruptura, ou quebra de estoque, é a situação em que um produto comercializado pela empresa não se encontra disponível na área de vendas ao consumidor no momento da compra. Estimativas dos níveis de ruptura têm constantemente ultrapassado a média de $8 \%$ no varejo e, apesar dos esforços, esse valor tem permanecido elevado por um longo período de tempo (VASCONCELLOS; SAMPAIO; PASTORE, 2007). Entre as várias causas estão a proliferação de produtos, redução do ciclo de vida e a falta de coordenação da cadeia de suprimentos.

Novaes (2007) afirma que o problema da ruptura não é resolvido trivialmente, as referências citadas pelo autor confirmam os índices em torno de $8 \%$ de ruptura em supermercados em uma tarde típica de venda. A disputa por espaços nos pontos de venda, a variação temporal da demanda, o nível de serviço oferecido pelo fornecedor, as ineficiências dos varejistas e o comportamento do consumidor em relação à falta de produto são considerados os principais fatores que geram a ruptura (NOVAES, 2007).

Um estudo norte-americano sobre os níveis de ruptura (em inglês, out-of-stocks - OOS) apresentou um estudo detalhado a respeito do tema nos principais mercados mundiais (GRUEN, 2007). Ele apresenta as taxas de ruptura de quatro localidades mundiais, os EUA, com 7,9\% de ruptura; a Europa, incluindo leste europeu, com 8,6\%; outras regiões importantes, como América Latina, com 8,2\%; e dados encontrados, através da internet, de outras localidades diversas do mundo (não explicitadas no trabalho), com taxas de 8,3\% em média. Afirma, ainda, que em produtos em promoções, a taxa de ruptura nos EUA sobe de $7,9 \%$ para $17,1 \%$.

Um artigo publicado pela ECR Brasil (2008) traz a necessidade de que se calcule as quantidades de produtos expostas em função de seu tamanho, porte e giro, e que os parâmetros sugeridos sejam avaliados regularmente, uma vez que, em geral, os softwares trabalham apenas com médias. Caso contrário, poderão ocorrer variações importantes ao longo do tempo (como vendas concentradas em determinados dias ou horários), sendo preciso calcular (via sistema) as quantidades de produtos vendidas por dia (ou período de tempo) e os tempos de entrega médios de cada fornecedor.

Também é necessário, segundo o artigo, calcular quantos dias de vendas comportam os estoques disponíveis, determinando a data e a quantidade de produtos a ser comprada. Para que o sistema funcione corretamente, é necessário que os registros de vendas, níveis de serviço e prazos envolvidos com cada operação sejam corretos e confiáveis. Itens sazonais ou promocionais, cuja previsibilidade de demanda e de entrega, em geral, sofre grande variação, exigem cuidado especial. Assim, a ECR Brasil acredita que se deve ter controles de estoques de retaguarda separados dos da gôndola, com registros de entradas e saídas independentes, de modo a saber exatamente onde estão os produtos a cada momento. 
Este trabalho tem por objetivo propor um planejamento estratégico para a reposição de produtos em uma rede de lojas do setor supermercadista. 0 foco principal da proposta é garantir que os produtos, que estão no Centro de Distribuição (CD) da empresa, estejam disponíveis nas 31 lojas da empresa estudada, diminuindo assim o nível de ruptura CD-Loja, que, anteriormente à aplicação dessa proposta, atingia níveis de $10 \%$ a $15 \%$ do total de produtos comercializados. Para o desenvolvimento da proposta de planejamento estratégico de reposição utilizou-se a previsão de séries temporais, através do algoritmo matemático Redes Neurais Artificiais de Bases Radiais, aplicadas a cada produto de cada uma das lojas, obtendo assim uma sugestão de reposição automática que antecipa a demanda de compra do consumidor.

0 trabalho está organizado da seguinte forma: na seção 2 é descrito o problema real da reposição dos produtos centralizados em uma rede de lojas supermercadista, com todas as particularidades pertinentes para a sua solução. Na seção 3 faz-se uma revisão bibliográfica de trabalhos correlatos ao aqui abordado, com breves relatos destes. Na seção 4 é feita a descrição da metodologia proposta, desde o processo de coleta e preparação dos dados, os fundamentos teóricos sobre a previsão de vendas, e a descrição do cálculo de parâmetros, nos quais se baseará a metodologia de reposição do estoque da loja. Também na seção 4 é apresentada a estratégia final de reposição e a obtenção dos resultados. Por fim, na seção 5 é realizada a análise dos resultados e são apresentadas as conclusões.

\section{Descrição do problema}

Como as modernas técnicas de gestão comercial privilegiam o baixo estoque, os empresários devem ajustar, ao máximo, os produtos e serviços às necessidades dos clientes (DALLA COSTA, 2004). É preciso ter em mente que, quando as pessoas vão às lojas, elas compram além do planejado, podendo o comércio lucrar bastante com o estímulo às compras por impulso. Por maior que seja o esforço do comerciante, de nada valerão as ações se não houver disponibilidade de produtos nas gôndolas (prateleiras) das lojas. Cabe ao CD viabilizar de forma competitiva o fluxo de mercadorias vindas dos fabricantes, até os seus diversos graus de capilaridade distributiva (FARAH JUNIOR, 2002).
A ruptura causa perdas maiores do que a não venda do produto faltante, pois pode causar a insatisfação do cliente que, por sua vez, pode acarretar a diminuição no volume da sua compra; o abandono do carrinho de compras e ir embora e/ou nunca mais voltar a comprar nessa loja. 0 Brasil apresenta índice de ruptura entre $7 \%$ e 8\%, na América Latina, esse índice varia de $12 \%$ a $14 \%$, enquanto na Europa a ruptura atinge de $15 \%$ a $20 \%$ dos produtos nas lojas (LEONARDI, 2008).

Nas empresas de varejo supermercadistas, o setor mais importante das lojas é a mercearia, no qual, em média, $80 \%$ dos produtos estão classificados. A empresa estudada como motivação para esta proposta possuía um índice de aproximadamente $12 \%$ de ruptura CD-Loja neste setor. Isto representa que cerca de 960 produtos, dos quase 8000 (oito mil) comercializados pela empresa no setor de mercearia, estavam disponíveis no $\mathrm{CD}$ e, por motivos diversos, não eram programados para a reposição ou a reposição era insuficiente, causando assim a ruptura. 0 índice de ruptura é mensurado sempre que um produto fica com estoque zerado na loja.

0 problema principal tratado neste trabalho é a sugestão automática de reposição de produtos. Gerar uma lista de produtos que devem abastecer a loja para que não ocorra a ruptura destes, e também, preocupar-se com um limite de estoque máximo de cada produto, para que não gere a superestocagem, são os objetivos do trabalho. Há na literatura muitos trabalhos, métodos e sugestões sobre a estratégia de reposição. De uma forma geral, os métodos podem ser qualitazexploratórios sobre pessoas, lugares e processos interativos; ou quantitativos, que focam na medição objetiva e na quantificação de produtos que devem estar disponíveis nas gôndolas das lojas (LEMOS; CAMPAGNOLO; MÜLLER, 2008).

Este trabalho visa propor uma metodologia que faça a junção entre a qualidade da operação logística e a quantidade de produtos sugerida para a reposição. Desta forma, ter-se-á um planejamento estratégico com a máxima precisão sobre o consumo a ser realizado pelos clientes, acarretando, com isso, a antecipação das operações logísticas necessárias e minimizando o nível de ruptura e a superestocagem.

\section{Reposição de produtos}

As estratégias de reposição de produtos devem ser efetivas no suprimento das lojas, porém devem ser 
controladas de modo a não superestocá-las. A grande maioria dos controladores de estoque comercializados e usados nas empresas possui um sistema de previsão simplificado, em geral, utilizando métodos estatísticos, como o Alisamento Exponencial Simples e as Médias Móveis. Estes métodos são utilizados para a previsão de séries temporais e são de fácil entendimento e aplicação, porém, para séries temporais com alta instabilidade, estes métodos acabam por não satisfazer o objetivo de prever com qualidade a série estudada. A previsão da demanda é uma etapa crítica para todas as etapas de uma cadeia de suprimentos devido à complexidade e incertezas intrínsecas a suas atividades (DIAZ; PIRES, 2003).

Uma estratégia de reposição de produtos baseada nesses métodos pode ocasionar falhas de suprimento de produtos, seja pela falta ou excesso de estoque. Isso pode ocorrer com grande facilidade devido à característica de vendas dos produtos no setor supermercadista, onde a instabilidade de vendas é muito grande (WANKE, 2003). A sazonalidade, o preço do produto, o dia da semana, a concorrência, o atendimento e as promoções são componentes que influenciam diretamente no comportamento de vendas (FIGUEIREDO, 2006). A série temporal de vendas é muito sensível a qualquer um desses aspectos, fazendo com que um método mais robusto deva ser utilizado para a obtenção na previsão de vendas.

A reposição de produtos deve ser planejada levando-se em consideração cada dia de venda de cada um dos produtos. Para isso, é necessário um método de previsão adequado, que leve em consideração todas as características anteriormente mencionadas, pois repor os produtos baseando-se no comportamento futuro das vendas é uma estratégia mais eficiente do que repor os produtos referenciando-se somente no comportamento passado de vendas.

O sistema de reposição encontrado na empresa estudada era baseado nas médias móveis e nos pedidos dos gerentes das lojas, que se mostrou ineficiente para uma generalização da reposição dos produtos. A estratégia de reposição automática era calculada com base nas médias móveis dos últimos 30 dias e quando o estoque ficava menor do que a média, então era sugerida a reposição do produto em uma quantidade preestabelecida.

Um problema encontrado constantemente com a aplicação desta técnica é o fato de que, por motivos diversos, a venda seja muito maior do que a tendência natural, fazendo com que o valor das médias fossem alterados e o estoque se tornasse muito grande, causando a superestocagem. De modo análogo, se em um ou mais dias seguidos a venda é muito menor do que o normal (devido a chuvas ou outro fator externo qualquer), o valor de média sofreria uma distorção para baixo, aumentando a probabilidade de ruptura. Principalmente se coincidir com a chegada do fim de semana, pois não há reposição de produtos do CD para as lojas aos domingos.

\section{Ruptura}

A ruptura é cada vez mais reconhecida como um problema crítico, tanto por pesquisadores como por práticos. Deve ser gerenciada como uma combinação de esforços para reduzir o número de ocorrências, minimizando a falta do produto nas gôndolas e, ainda, oferecendo compensações para alterar a reação do consumidor de, por exemplo, deixar a loja quando a ruptura for inevitável e/ou demasiadamente dispendiosa de ser eliminada.

Enquanto a literatura internacional é rica em pesquisas nestas duas vertentes (seção 3 , a seguir), a literatura brasileira é carente de informações sobre a ruptura em seu mercado. Quando ocorre a ruptura, em $45 \%$ dos casos os consumidores substituem seus produtos, em 31\% trocam de lojas e em 14\% dificilmente retornam (VASCONCELLOS; SAMPAIO; PASTORE, 2007). A ruptura de gôndola foi, é, e provavelmente sempre será um importante problema gerencial a ser resolvido.

No caso estudado, priorizou-se o estudo sobre o setor de mercearia dos supermercados, pois estes possuem uma representatividade muito maior na operação e faturamento das lojas. Encontrou-se um nível de ruptura que atingia quase $15 \%$ em alguns casos e nunca diminuíam de $8 \%$, mesmo nas lojas mais eficientes da rede. A ruptura considerada e medida neste trabalho foi a ruptura CD-Loja, isto é, produtos que estão no centro de distribuição e entram em ruptura nas lojas por falta de uma reposição mais eficiente, sendo desconsiderada a ruptura causada pela reposição de produtos diretamente do fornecedor. Os pedidos das lojas para o CD eram compostos por dois valores, um pela reposição automática (médias móveis) e outro pelo pedido de reforço do gerente da loja.

As operações de reposição no CD (separação de produtos, carregamento dos caminhões e expedição) aconteciam em maior quantidade nas segundas-feiras, 
quando eram repostos os produtos vendidos durante os fins de semana. A média de caixas separadas e carregadas nas segundas-feiras era superior a 45.000 (quarenta e cinco mil), enquanto que nas quartas-feiras e quintas-feiras, a média girava em torno de 13.000 (treze mil). Isso significava um pico de atendimento e de operações logísticas no início de cada semana, gerando um gargalo operacional no CD.

\section{Trabalhos correlatos}

A logística é um tema que ganha cada vez mais importância na literatura científica e comercial. Ângelo e Siqueira (2000), fazem uma avaliação das condições logísticas nos supermercados brasileiros para verificar as condições de se implantar a filosofia efficient consumer response (ECR). Farah Junior (2002), traz uma discussão sobre os centros de distribuição e os desafios que podem reduzir custos logísticos e agilizar os processos de entrega de produtos com a instalação de CD's.

Dalla Costa (2004) faz um estudo sobre o caso "Pão de Açúcar", como a empresa cresceu devido à construção do suporte logístico e, ainda, como os investimentos neste setor auxiliaram para que a distribuição pudesse acompanhar os avanços no número de lojas e no volume de vendas. A logística enxuta foi tema do trabalho de Figueiredo (2006), o qual enfatiza a melhoria contínua na cadeia de suprimentos. Afirma que a logística enxuta tem muitos desafios, mas conta também com uma série de aliados e ações a serem praticadas para lograr seu objetivo. São eles: agilidade, sincronização, análise de processos com o objetivo de identificar onde se perde tempo e onde se acumulam estoques, colaboração com fornecedores e clientes para o planejamento da demanda. E, também, investimentos em tecnologia de informação para monitorar veículos, controlar estoques e dispor de indicadores on line para medir desempenhos e poder antecipar ações corretivas no rumo.

0 planejamento de estoque consiste em determinar quando e quanto pedir. A maioria dos autores clássicos que tratam deste tema, entre eles Ballou (1993), Chopra e Meindl (2011) e Bowersox, Closs e Cooper (2007), divulgam o conceito de ponto de reposição como sendo a multiplicação de uma taxa de demanda, em unidades por tempo e do prazo médio de entrega, em unidades de tempo. Neste caso, tem-se um valor em unidades do produto, sendo que se a quantidade em estoque do produto disponível atingir esta quantidade, o ponto de reposição, então é preciso fazer um pedido de um lote econômico adequado de compra.

Este modelo básico de reposição pode ser aprimorado de acordo com a complexidade de informações pertinentes que se deseja incorporar ao modelo. Por exemplo, pode-se querer incorporar ao modelo a incerteza da demanda, o prazo de entrega, os custos conhecidos por falta de estoque, o giro de estoques no caso de controle agregado, tarifas de transportes, custos por pedidos, médias de vendas, duração do ciclo de atividades, entre outros fatores.

A gestão da informação aplicada à logística é o tema também trazido por Carvalho, Oliveria e Jamil (2007), no qual dizem que a gestão da informação é um aspecto crítico para a otimização na distribuição física de uma cadeia de valores para a elevação do nível de serviço oferecido aos clientes. Neste mesmo setor, Benetti et al. (2008), sugerem um modelo de avaliação do desempenho logístico de um CD no setor supermercadista, estabelecendo uma relação entre a teoria e a prática. Ainda Carrera et al. (2008), voltam a focar o sistema Just-in-time, neste caso aplicando na administração da busca da excelência de seus processos, comentando que esta filosofia tornou-se um comprometimento entre todos os membros que fazem parte do canal de abastecimento de determinado produto ou serviço.

Para auxiliar nos processos logísticos de reposição de produtos, a análise de séries temporais vem sendo um tema bastante abordado neste contexto. Já Fernandes, Portugal e Navaux (1995), utilizam a previsão de séries temporais através de um algoritmo de Redes Neurais Artificiais (RNAs), dando destaque as suas características estatísticas. Corrêa e Portugal (1998), apresentam uma avaliação empírica da capacidade preditiva de modelos de RNAs e modelos estruturais, mostrando uma capacidade levemente superior ao das RNAs. Dias (1998), faz uma proposta de processos de previsão de vendas para bens de consumo que visa atender à escolha e ao ajuste de técnicas de previsão e também para função de previsão como um todo. Ele traz uma comparação entre métodos quantitativos e qualitativos de previsão, bem como uma comparação entre os softwares e suas funções e os métodos das empresas que utilizam a previsão como apoio à tomada de decisão.

Coelho e Canciglieri Junior (2000), apresentam a aplicação de Redes Neurais de Bases Radiais (RBFs) para o procedimento de previsão de séries temporais, indicando que o modelo proposto é atrativo em 
identificações de sistemas complexos, aplicações financeiras e sistemas de informações. Um estudo comparativo entre métodos estatísticos e RNAs foi apresentado por Lima e Almeida (2004), visando explorar a possibilidade de usar uma metodologia capaz de decompor uma série temporal, via wavelets, conjuntamente com os modelos já existentes de previsão e comparar a qualidade das previsões obtidas. Os resultados mostraram que as RNAs possuem um desempenho superior quando há períodos de menor volatilidade no mercado financeiro.

A previsão dos preços agropecuários, analisando os aspectos teóricos do Data Mining e a aplicação de RNAs, é o objetivo do estudo realizado por Lazzarotto, Oliveira e Lazzarotto (2006), os quais constataram que, apesar de existirem algumas limitações, as RNAs podem constituir interessante alternativa para a previsão dos preços. Faria et al. (2008), mostram o uso das técnicas estatísticas Alisamento Exponencial Simples e Média Móvel na previsão de séries temporais, verificando que, apesar de serem métodos simples de previsão, os resultados foram razoáveis. Verificam, também, que aumentando a janela de tempo de observações no método de Médias Móveis, aumenta também a medida de erros de previsão.

Vasconcellos, Sampaio e Pastore (2007), publicaram um relatório sobre a logística de varejo analisando a questão da ruptura de estoque e suas causas no setor supermercadista paulista sob a ótica dos gestores do negócio. Este trabalho examina, além do nível de incidência da ruptura, também suas principais causas e responsabilidades. Esta pesquisa sugere que existem oportunidades para os supermercados reduzirem suas taxas de ruptura através de ações de prevenção e/ou a implementação de planos de contingência visando alterar a reação do consumidor frente à ruptura. 0 trabalho sugere uma investigação mais aprofundada sobre o tema no cenário brasileiro, justificando que a questão de ruptura é um dos fatores mais importantes para explicar a satisfação dos consumidores.

Leonardi (2008), comenta que as rupturas causam perdas nos pontos de venda e na indústria. Apresenta dados sobre as rupturas no Brasil e no exterior e sugere que se deve trabalhar sobre os pontos críticos no sentido de sanar problemas de estoque e abastecimento, e, assim, oferecer um mix correto e na quantidade adequada para um ponto de venda. $\mathrm{O}$ autor afirma que, após um estudo sobre o histórico de vendas, deve-se estabelecer uma previsão de vendas, considerando que quanto maior o sortimento de produtos, mais se estará evitando a ruptura e, consequentemente, menores as chances do consumidor ir para a concorrência.

\section{Apresentação e implementação da metodologia proposta e obtenção dos resultados}

O sistema de reposição de estoque deve ser efetivo nas organizações, ou seja, deve suprir as demandas de vendas e, ao mesmo tempo, não causar superestocagem nas lojas. A administração moderna tem buscado constantemente novas ferramentas que possam auxiliá-las na busca da excelência de seus processos (CARRERA et al., 2008). A metodologia sugerida neste trabalho visa estabelecer parâmetros para a reposição automática dos produtos, minimizando os índices de ruptura e auxiliando na tomada de decisão do gerente da loja.

Para cada produto de cada loja da rede varejista, calculam-se os níveis de estoque de acordo com os dias de cobertura desejado pela política de estoque da loja. Para este cálculo, toma-se por base o histórico de vendas, cujos dados são preparados, ajustados e, em seguida, aplicados em um sistema de previsão de vendas. 0 método de previsão utilizado neste trabalho são as Redes Neurais Artificiais de Bases Radiais (RBFs).

A quantidade de vendas prevista (obtida através das RBFs) é utilizada para definição, dia a dia, dos parâmetros de reposição, e estes parâmetros, por sua vez, são cruzados com as informações de estoque real do fim do dia, de modo a sugerir a reposição automática, via sistema, de cada um dos produtos. 0 processo geral da metodologia está representado na Figura 1 e a explicação detalhada de cada passo é apresentada logo a seguir.

0 principal foco da metodologia apresentada neste trabalho é a utilização de uma técnica de previsão de vendas para o cálculo dos valores de estoque mínimo, limite e máximo para reposição do estoque de cada produto nas lojas. A metodologia de previsão utilizada

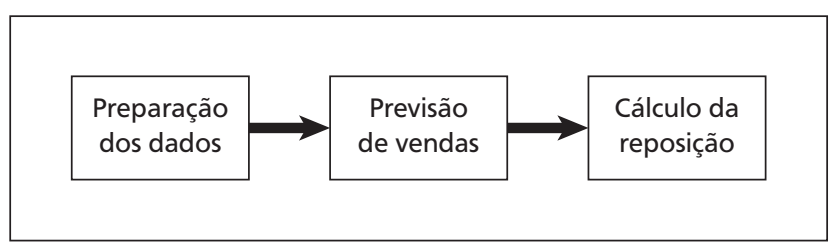

Figura 1 - Esquema geral da metodologia proposta Fonte: Dados da pesquisa. 
é complexa e, para este trabalho, as RBFs foram programadas na linguagem Visual Basic 6. As RBFs realizam a previsão de vendas dado o histórico de vendas de cada produto de cada loja. Vale salientar que outros programas podem possuir esse método implementado, como, por exemplo, o software matemático $M A T L A B$, porém, a suavização e tratamento dos dados devem ser programados separadamente. Com isso, este trabalho foi desenvolvido objetivando a proposta de reposição automática de produtos, ficando a ferramenta de previsão de vendas utilizada apenas para auxiliar no planejamento estratégico proposto.

Foram coletados dados de 56 semanas, totalizando 392 dias de vendas. Esse volume de dados se justifica da seguinte forma: são 52 semanas para o treinamento da rede neural, ou seja, um ano de informações para captar as sazonalidades naturais características do produto, e mais 4 semanas para realizar os testes de validação das redes neurais, isto é, um mês de validação e obtenção do erro de previsão. 0 algoritmo fornece como resposta a previsão do valor de uma semana de vendas.

\section{Coleta e tratamento dos dados}

Uma série temporal consiste de medidas ou observações de um fenômeno que se realiza sequencialmente sob um intervalo de tempo. A série temporal formada pelo histórico de vendas de um produto é a base de dados utilizada para alimentar o método de previsão de vendas (LIMA; ALMEIDA, 2004). No mercado de varejo existem muitas variáveis que podem influenciar no aumento ou na diminuição de venda de certo produto. Muitas delas são variáveis qualitativas, como: tendência de mercado, preferência do cliente e promoções. Estas variáveis não trazem indicadores precisos "de quando" e "de quanto" podem alterar a quantidade de produtos vendidos e acabam por não retratar o valor real de venda do produto em épocas normais de vendas.

A sazonalidade dos produtos é uma característica identificada facilmente pela análise da série temporal, porém de difícil reprodução no momento de prever o comportamento das vendas (LAZZAROTTO; OLIVEIRA; LAZZAROTTO, 2006). Além disso, promoções exclusivas de uma loja ou acontecimentos inesperados nas redondezas da loja podem também influenciar o comportamento de vendas de um produto. Com isso, esses fatores devem ser identificados e retirados da série original, suavizando os dados e obtendo o comportamento real de venda do produto.

Neste trabalho, dos 392 dados, foram retirados os valores das quantidades vendidas obtidas nos dias em que o produto esteve em promoção e, dos dados restantes, colocados em rol (ordem crescente), foram retirados 5\% dos dados do extremo inferior e 5\% dos dados do extremo superior, minimizando a possibilidade de ruído branco (técnica estatística de box plot).

Calcula-se, então, a média e o desvio padrão dos dados restantes, considerados dados de vendas sem influências. Geram-se, aleatoriamente, dados dentro do intervalo centrado na média e com raio igual a um desvio padrão, que irão substituir os dados que foram retirados. Para o tratamento dos dados deve-se salientar que a posição da informação dentro da série temporal é imprescindível para a qualidade da previsão pretendida. No caso em que a subtração da média pelo desvio padrão for negativa, limita-se o intervalo inferiormente pelo valor zero.

Na Figura 2 é apresentado um exemplo de dados do produto "Água Sanitária”, onde são comparadas a série temporal original, sem nenhum tipo de tratamento, e a série temporal após o tratamento, utilizada para alimentar o algoritmo de redes neurais.

\section{Previsão de vendas}

A gestão da informação é um aspecto crítico para a otimização da distribuição física de uma cadeia de suprimentos e para a elevação do nível de serviço oferecido aos clientes (CARVALHO; OLIVERIA; JAMIL, 2007). A previsão de vendas é tema de muitas publicações e de muita discussão no âmbito empresarial (CORRÊA; PORTUGAL, 1998). Possuir uma previsão de vendas confiável é uma informação cada dia mais importante, pois com ela a empresa pode melhorar o nível de serviço, antecipando ações de modo a suprir a demanda dos clientes. A reposição de produtos nas lojas deve ser capaz de atender a demanda diária de venda, cobrir um período determinado e, também, não causar superestocagem nas lojas (DIAS, 1998).

Existem diversas técnicas de previsão de vendas, sejam qualitativas ou quantitativas. Neste trabalho, conforme já comentado, são utilizadas as RBFs. Esta técnica tem várias características comuns com os modelos estatísticos e econométricos tradicionais (FERNANDES; PORTUGAL; NAVAUX, 1995). As RNAs funcionam conceitualmente de forma similar ao 


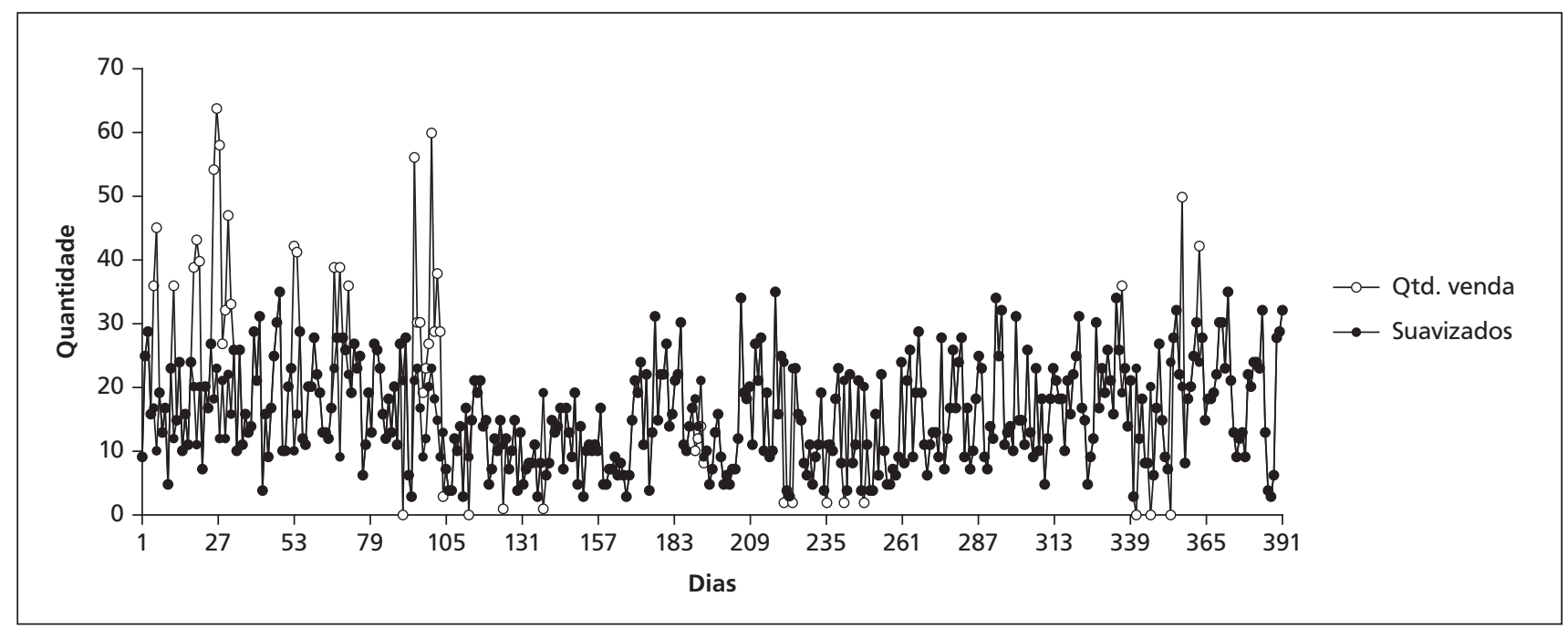

Figura 2 - Exemplo de suavização dos dados

Fonte: Dados da pesquisa.

cérebro humano, tentando reconhecer regularidades e padrões de dados. As RNAs são capazes de aprender com a experiência e fazer generalizações baseadas no seu conhecimento previamente acumulado.

As características que tornam as RNAs atraentes para previsão de séries temporais são, segundo Coelho e Canciglieri Junior (2000), habilidades em tratar sistemas não lineares, tolerância a falhas, adaptabilidade, aprendizado, auto-organização, generalização, treinamento, processamento paralelo e abstração. Todas essas características são observadas devido às estruturas interconectadas, chamadas neurônios, os quais se conectam através de pesos, ajustados durante o período de treinamento da RNA, segundo um conjunto de regras de aprendizagem que ajustam interativamente estes pesos até que sejam obtidas as relações de causa e efeito dos dados. Se as condições forem alteradas, de tal modo que o desempenho do modelo não seja mais adequado, pode-se submeter as RNAs a um novo treinamento para "corrigir" seu desempenho. Assim sendo, pode-se submeter as RNAs a uma atualização periódica, resultando num modelo autoajustável com o passar do tempo.

As Redes Neurais de Base Radial (RBF ou Artificial Neural Networks of Radial Basis Functions) são RNAs com múltiplas camadas que não são treinadas por retropropagação (backpropagation) e que não têm unidades de processamento com função de ativação do tipo sigmoidal. Redes que funcionam de acordo com esta estratégia utilizam unidades com campos receptivos locais (local receptive fields), nos quais as unidades que recebem entradas diretamente da entrada do sistema estão habilitadas a "ver" apenas parte destas entradas.

Esta abordagem emprega, na maioria dos casos, treinamento supervisionado e não supervisionado. As redes são muito empregadas como interpoladores/ aproximadores e em tarefas de classificação. Algumas extensões do método são aqui mostradas. Esta abordagem é inspirada na propriedade de alguns neurônios biológicos chamada de resposta localmente sintonizada (locally tuned response). Tais células nervosas respondem seletivamente a um intervalo finito do espaço de sinais de entrada.

Os modelos de RBF de hoje se diferenciam dos primeiros, pois são de natureza adaptativa que permite a utilização, em muitas situações, de um número relativamente menor de unidades de processamento localmente sintonizadas, os chamados centroides.

A previsão do preço da energia elétrica é o tema em um trabalho publicado por Meng, Dong e Wong (2009). A novidade deste trabalho é a união da lógica fuzzy com o algoritmo de c-médias para definição dos centroides. Meng, Dong e Wong (2009) Utilizam a RBF para previsão de vendas de uma bebida a base de mamão e leite. Para tal, os autores desenvolvem um algoritmo híbrido utilizando o PSO (Particle Swarm Optimization) e o AG (algoritmos Genéticos) para definir os parâmetros da RBF. Os resutlados mostram previsões muito próximas da venda real, satisfazendo os objetivos iniciais do trabalho. Ghods e Kalantar (2010) publicam um artigo aplicando a RBF par a previsão de picos de energia no Irã. A quantidade de 
centroides é definida empiricamente e estes são definidos pela média de cada fator de influência da série temporal gerada.

A RBF utilizada tem como característica essencial, conforme a Figura 3, a seguir, que a camada de saída é uma combinação linear dos sinais da camada oculta, sendo que esse tipo de rede neural utiliza somente uma camada oculta. A RBF permite um procedimento rápido de atualização de pesos, separa os padrões de entrada e apresenta uma estrutura apta à construção de mapeamentos locais dos dados de entrada e saída.

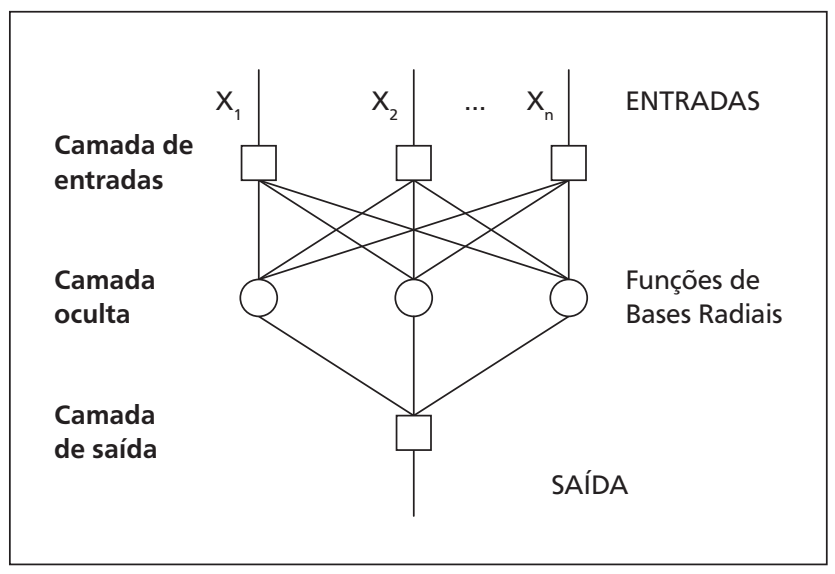

Figura 3 - Arquitetura da RBF com uma camada oculta ou intermediária

Fonte: Dados da pesquisa.

A função de ativação utilizada na arquitetura da RBF implementada neste trabalho é a função Gaussiana. A Ativação se dará da seguinte forma: a saída do neurônio produzirá resultados iguais para aqueles valores de potencial de ativação $\{u\}$ que estejam posicionados a uma mesma distância de seu centro, sendo que a curva é simétrica em relação a este. É dada por (1) (SILVA; SPATTI; FALUZINO, 2010).

$$
f(x)=e^{\frac{(u-c)^{2}}{2 \sigma^{2}}}
$$

Onde $c$ é um parâmetro que define o centro da função gaussiana e $\sigma$ denota o desvio padrão associado à mesma, isto é, o quão espalhado (dispersada) está a curva em relação ao seu centro.

Neste trabalho foram utilizados os dados de quantidade de vendas agrupados por semana, assim, tem-se 56 valores (semanas) para a utilização das RBF. Os dados de entrada (atributos) são formadas por 4 valores, isto é, os valores de 4 semanas seguidas de vendas e a saída utilizada foi o valor da semana seguinte, ou seja, o da quinta semana. Por exemplo, o primeiro padrão de entrada da RBF são os valores das semanas 1, 2, 3 e 4, nesta ordem, e a saída utilizada é a semana 5. 0 segundo padrão de entrada é formado pelos valores das semanas, nesta ordem, 2, 3, 4 e 5, e a saída correspondente é a semana 6, e assim por diante, até o ultimo padrão que possui como saída o valor da semana 52. Com a RBF já treinada, o teste é feito com as semanas $53,54,55$ e 56 como saídas e, neste teste, é obtido o valor do erro de previsão. A previsão é realizada após o treinamento e teste da RBF com o padrão de entrada formado pelos valores das semanas $53,54,55$ e 56 , e o valor previsto é para a semana 57.

\section{Cálculo dos limites}

Uma vez que se tenha o valor de previsão de venda para a semana seguinte de cada um dos produtos de cada loja, calculam-se, então, os valores limites de estoque. Para isso, deve-se dividir o valor previsto para uma semana em valores de venda para cada um dos dias daquela semana. Utiliza-se a proporcionalidade do dia como previsão diária. 0 valor previsto é considerado $100 \%$ das vendas para a próxima semana, o valor percentual de cada dia da semana, de segunda-feira a domingo, é calculado pela média percentual da participação de vendas das últimas 4 semanas. Por exemplo, o percentual da segunda-feira do valor de venda da semana 53 é $14,4 \%$, da semana 54 é $18 \%$, das semanas 55 e 56 são, respectivamente, $16,5 \%$ e $15,1 \%$. A média desses 4 percentuais é $16 \%$, logo, a quantidade de produtos prevista para a venda da segunda-feira da semana 57 é $16 \%$ do valor previsto nas Redes Neurais.

De forma similar, calculam-se os valores de vendas para os demais dias da semana. Como no fim de semana a reposição de produtos é feita somente no sábado (aos domingos não é realizada a operação de reposição), então as quantidades previstas de venda de sábado e domingo são somadas e o fim de semana (sábado e domingo) é considerado como um único dia. De acordo com a política de estoque da empresa, define-se a quantidade de dias que a reposição do produto deve suprir. Com base nessa cobertura de dias (3 dias, por exemplo), cria-se o conceito de valores de estoque mínimo, estoque limite e estoque máximo, e se faz os respectivos cálculos. 
O estoque mínimo de um produto para um determinado dia é o valor de previsão para aquele dia; o estoque máximo é a soma dos valores de previsão subsequentes dos dias de cobertura; e o estoque limite é a média aritmética entre o mínimo e o máximo. Como alternativa, o estoque limite pode ser utilizado também com um conceito de cobertura mínima, isto é, uma quantidade de produtos que supra a venda de certo número de dias, sendo esta soma menor do que o estoque máximo.

Seja a previsão de vendas para o produto "Água Sanitária", para uma determinada semana, de 408 unidades, conforme Quadro 1. Conforme explicado anteriormente, divide-se esse valor e, proporcionalmente, obtém-se as quantidades de vendas previstas para cada dia da semana, determinando assim o estoque mínimo que a loja deve possuir em cada dia. Neste exemplo, determinou-se que a cobertura de estoque é de 3 dias e que a cobertura mínima, ou seja, o estoque limite, deve cobrir 2 dias. Assim, o estoque limite de segunda-feira é a soma do valor previsto para segunda e terça (75+ $51=126$ ) e o estoque máximo é a soma dos valores de estoque mínimo de segunda, terça e quarta $(75+51+$ $48=174$ ). Para estoque máximo de sexta-feira, e estoque limite e máximo do fim de semana, utilizam-se os valores de segunda e terça, ou então, roda-se a previsão de venda novamente no meio de semana.

\section{Estratégia de reposição e exemplos}

De posse das informações de estoque, cruzam-se essas informações com o estoque real do produto no fim do dia. Se o estoque real for menor que o estoque limite, calcula-se a diferença entre o estoque máximo e o estoque real, e este valor encontrado é a sugestão de reposição do produto para o dia seguinte. Com isso, pode-se estabelecer a estratégia de reposição que mais convier para a empresa. Os dias de cobertura para o cálculo de estoque máximo podem ser definidos por produto ou por característica mercadológica. Assim, pode-se definir para produtos com alto giro, poucos dias de cobertura e, para produtos de baixo e baixíssimo giro, um número maior de dias de cobertura.

Ao se definir os dias de cobertura, deve-se considerar a operação logística envolvida no processo. Assim, quando é sugerida a reposição automática de um produto, considera-se que a reposição será efetuada na gôndola no meio do período da manhã em diante, e este período deve ser suprido com o estoque atual. 0 acerto de dias de cobertura influencia diretamente na periodicidade de reposição, pois quanto maior os dias de cobertura, menor é a quantidade de reposições e, consequentemente, maior o risco de se ter uma superestocagem; já por outro lado, se forem poucos os dias de cobertura, maior será a quantidade de reposições e, consequentemente, mais enxuto será o estoque, com maior risco de se ter a ruptura do produto.

Deste modo, encontrar para cada produto ou para cada grupo mercadológico a quantidade de dias de cobertura de estoque máximo da loja é um ajuste que deve ser planejado conjuntamente entre o gerente logístico e o gerente da loja, ficando o sistema de reposição proposto adequado para qualquer decisão tomada. 0 caso estudado e implementado foi em uma rede supermercados com 31 lojas e cada loja possuindo em média 8000 (oito mil) produtos diferentes, conforme já comentado na seção 2 deste trabalho. Foi definido um período de cobertura de 4 dias para produtos de alto giro, 5 dias para médio giro, 6 dias para baixo giro e 15 dias para baixíssimo giro. 0 programa desenvolvido demora em média 15 minutos para a previsão de todos os produtos de uma loja, sendo que a programação de reposição é dada semanalmente.

Na Figura 4, a seguir, tem-se um exemplo gráfico da programação de reposição de um produto de médio

Quadro 1 - Exemplo de cálculo dos valores de estoque mínimo, limite e máximo

\begin{tabular}{lcccccc}
\hline & \multicolumn{3}{c}{ Produto: Água Sanitária } & & \\
\hline & Segunda & Terça & Quarta & Quinta & Sexta & Fim de Semana \\
\hline Est. Mínimo & 75 & 51 & 48 & 59 & 51 & 124 \\
Est. Limite & 126 & 99 & 107 & 110 & 175 & 250 \\
Est. Máximo & 174 & 158 & 158 & 234 & 250 \\
\hline
\end{tabular}

Fonte: Dados da pesquisa. 


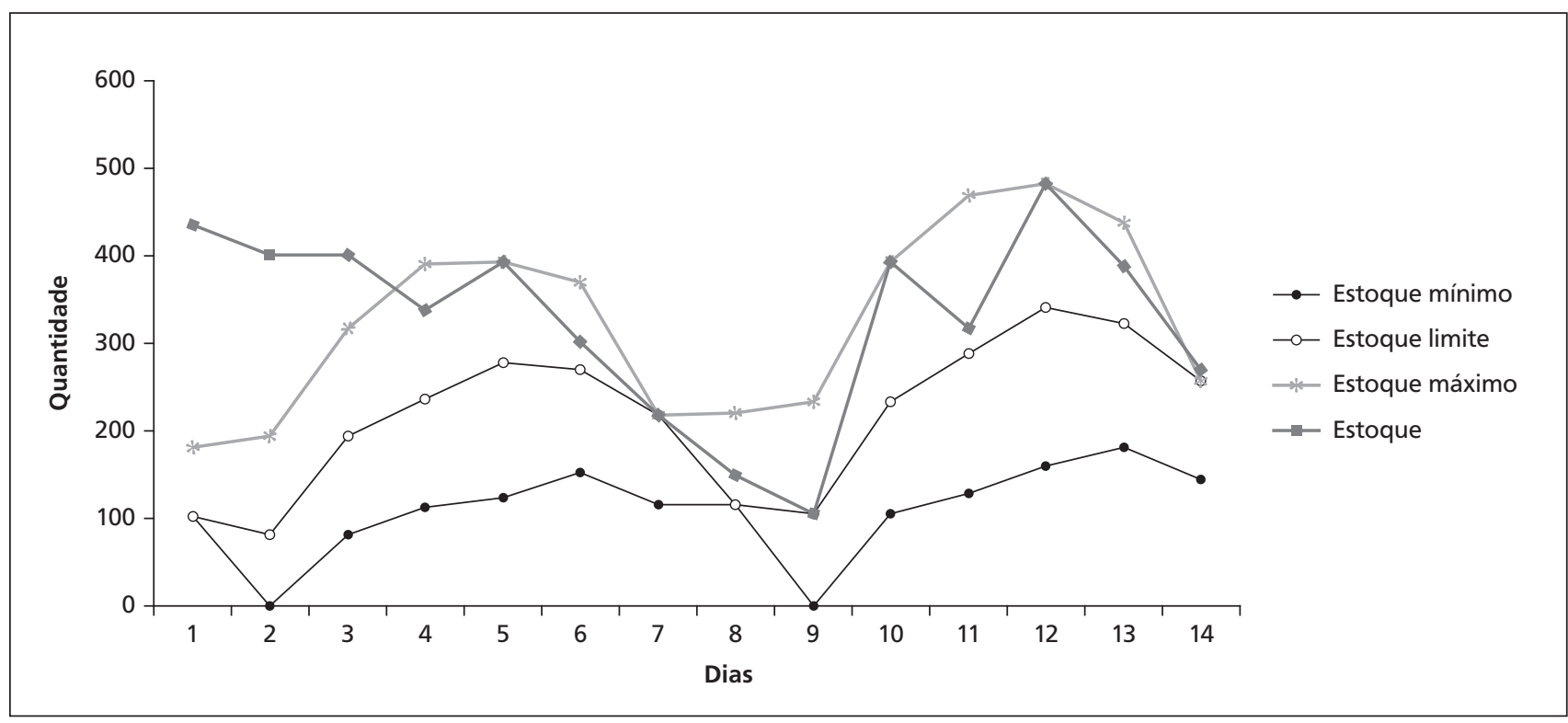

Figura 4 - Exemplo gráfico da reposição de duas semanas para o produto água sanitária

Fonte: Dados da pesquisa.

giro para duas semanas seguidas. No primeiro dia de aplicação do planejamento estratégico proposto, vê-se que o estoque real da loja, para este produto (Água Sanitária), está superestimado. Esta é uma das situações encontradas antes da aplicação do método, sendo que, neste caso, estava ocorrendo a superestocagem com o produto. A linha de estoque real é considerada no início do dia ou logo após a reposição efetuada. Percebe-se que a partir do quarto dia de aplicação do planejamento estratégico de reposição, o nível de estoque real se encontra entre o limite e o máximo.

Toda vez que, em certo dia, o nível de estoque real está igual ao estoque máximo, é porque no dia anterior a venda do produto fez com que esse nível ficasse abaixo da linha de estoque limite, gerando a sugestão de reposição. Deste modo, o estoque real passou a ficar, em média, na ordem de grandeza entre 50 a 200 unidades a mais que o estoque mínimo, considerando que a venda deste produto é, em média, entre 50 a 80 produtos por dia. 0 nono dia tem como previsão o valor zero, isso acontece por que este dia é feriado (loja fechada) e o planejamento estratégico proposto permite inserir esta informação no modelo. Ainda no gráfico desta Figura 4, verifica-se que as linhas de estoque máximo e de estoque mínimo se aproximam nos dias 6, 7 e 8, ocorrendo também nos dias 13 e 14. Isso acontece porque dia 6 é sábado e o estoque máximo é influenciado pelo estoque de segunda-feira dia 8. De modo análogo, tal fato acontece para o dia 13 também.

\section{Conclusões}

A proposta deste trabalho é sugerir um planejamento estratégico de reposição de produtos de uma rede de lojas de supermercados com base em previsões de vendas. A previsão toma por base a análise de séries temporais, a qual alimenta o algoritmo Redes Neurais Artificiais de Bases Radiais, obtendo um valor de previsão de venda. Este valor previsto é utilizado no cálculo de limites de estoque, os quais são atualizados de acordo com o dia da semana e previsão de consumo para os dias seguintes.

A estratégia proposta foi implementada no setor de mercearia em uma rede supermercadista com cerca de 8.000 produtos neste setor. A rede possui 31 lojas e as Redes Neurais fazem a previsão semanal de cada produto para cada loja. Cruzando, diariamente, as informações encontradas após a aplicação da metodologia em todos os produtos da loja, obtém-se uma sugestão de reposição de todos os produtos que devem ser levados do CD para as lojas. Os índices de ruptura encontrados, por ocasião da pesquisa eram, em média, de $12 \%$, isto é, cerca de 960 produtos faltando nas gôndolas todos os dias, em cada loja. Após a implantação da estratégia aqui proposta, o nível de ruptura caiu, em média, para menos de $0,7 \%$, representando, aproximadamente, apenas 56 produtos faltantes por dia.

0 mix das lojas aumentou significativamente, representando um aumento considerável de vendas e 
do nível de serviço oferecido aos clientes. Houve um aumento de pedidos de reposição das lojas para o CD, porém, com quantidades menores e mais frequentes. Os dias de cobertura foram definidos por classificação de giro dos produtos, distribuindo o carregamento dos caminhões de modo mais homogêneo entre todos os dias da semana em que ocorrem a Reposição (de segunda-feira a sábado), tendo em média 33.000 caixas por dia.

0 aumento do mix nas lojas, o aumento de pedidos de reposição em menores quantidades e com mais frequência, o aumento de vendas e, principalmente, a diminuição do nível de ruptura CD-Loja para cerca de $0,7 \%$ nos hipermercados e para $1,7 \%$ nos supermercados, mostram que o planejamento estratégico de reposição proposto é altamente viável e recomendável. Verifica-se que, utilizando uma previsão de vendas mais confiável e estabelecendo limites de estoque mais assertivos, tem-se uma "forte" ferramenta de auxílio à tomada de decisão, uma vez que une métodos qualitativos de gestão de estoques e quantitativos com algoritmos confiáveis.

\section{Referências}

ÂNGELO, C. F.; SIQUEIRA, J. P. L. Avaliação das condições logísticas para a adoção do ECR nos supermercados brasileiros. Revista de Administração Contemporânea, v. 4, n. 3, p. 89-106, 2000.

BALLOU, R. H. Logística empresarial: transporte, administração de materiais e distribuição física. São Paulo: Atlas, 1993.

BENETTI, K. C. et al. Modelo de avaliação de desempenho logístico de um centro de distribuição do setor supermercadista. In: SEMINÁRIOS EM ADMINISTRAÇÃO FEA-USP, 11., 2008, São Paulo. Anais... São Paulo: SEMEAD 2008.

BOWERSOX, D. J.; CLOSS, D. J.; COOPER, M. B. Gestão da cadeia de suprimentos e logística. Rio de Janeiro: Elsevier, 2007.

CARRERA, M. A. et al. Just-in-time: uma filosofia a serviço da administração. In: SIMPÓSIO DE ENGENHARIA DE PRODUÇÃO, 15., 2008, Bauru. Anais... Bauru: SIMPEP, 2008.

CARVALHO, R. B.; OLIVERIA, L. G.; JAMIL, G. L. Gestão da informação aplicada à logística: estudo de caso de uma grande agroindústria brasileira. In: ENCONTRO NACIONAL DE PESQUISA EM CIÊNCIA DA INFORMAÇÃO, 8., 2007, Salvador. Anais... Salvador: ENANCIB, 2007.
CHOPRA, S. MEINDL, P. Gestão da cadeia de suprimentos: estratégia, planejamento e operações. São Paulo: Ed. Pearson Prentice Hall, 2011.

COELHO, L. S.; CANCIGLIERI JUNIOR, O. Rede neural de base radial aplicada em previsão de séries temporais: algoritmo e aplicação. In: ENCONTRO NACIONAL DE ENGENHARIA DE PRODUÇÃO, 20., 2000, São Paulo. Anais... São Paulo: ENEGEP, 2000.

CORRÊA, W. R.; PORTUGAL, M. S. Previsão de séries de tempo na presença de mudança estrutural: redes neurais artificiais e modelos estruturais. Fundação Instituto de Ciências Econômicas, v. 2, n. 3, 1998.

DALLA COSTA, A. J. A importância da logística no varejo brasileiro: o caso do Pão de Açúcar. Cadernos da Escola de Negócios da Unibrasil, n. 2, p. 65-84, 2004.

DIAS, G. P. P. Proposta de processo de previsão de vendas para bens de consumo. In: ENCONTRO NACIONAL DE ENGENHARIA DE PRODUÇÃO, 16., 1998, Rio de Janeiro. Anais... Rio de Janeiro: ENEGEP, 1998.

DIAZ, C. A. P.; PIRES, S. R. I. Variação da demanda ao longo da cadeia de suprimentos: o efeito da amplificação da demanda. In: ENCONTRO NACIONAL DE ENGENHARIA DE PRODUÇÃO, 23., 2003, Ouro Preto. Anais... Ouro Preto: ENEGEP, 2003.

ECR BRASIL. Campanha para reduzir rupturas em R\$ 1 Bi. Como reabastecer as gôndolas. Revista Supermercado Moderno, v. 4. 2008. Disponível em: <www.sm.com.br/publique/media/2008_smdownloads_guia_pratico_4.pdf>. Acesso em: 27 out. 2009.

FARAH JUNIOR, M. Os desafios da logística e os centros de distribuição física. Revista FAE BUSINESS, n. 2, 2002.

FARIA, E. L. et al. Previsão de séries temporais utilizando métodos estatísticos. Rio de Janeiro: CBPF, 2008.

FERNANDES, L. G. L.; PORTUGAL, M. S.; NAVAUX, P. O. A. Previsão de séries de tempo: redes neurais artificiais e modelos estruturais. Pesquisa e Planejamento Econômico, v. 1, n. 2, p. 1-19, 1995.

FIGUEIREDO, K. A logística enxuta. Rio de janeiro: Centro de Estudos em Logística - COPPEAD/UFRJ. 2006.

GHODS, L., KALANTAR, M. Long-term peak demand forecasting by using radial basis function neural networks. Iranian Journal of Electrical \& Electronic Engineering, v. 6, n. 3, 2010 . 
GRUEN, T. W. Retail out-of-stocks: A worldwide examination of extent causes, and consumer responses. Colorado: University of Colorado, 2007.

LAZZAROTTO, L. L.; OLIVEIRA, A. P.; LAZZAROTTO, J. J. Aspectos teóricos do data mining e aplicação das redes neurais em previsões de preços agropecuários. In: CONGRESSO DA SOCIEDADE BRASILEIRA DE ECONOMIA E SOCIOLOGIA RURAL, 44., 2006, Fortaleza. Anais... Fortaleza: SOBER, 2006.

LEONARDI, E. Para garantir a festa de final de ano. Disponível em: <http://www.decnews.com.br>. Acesso em: 9 abr. 2009. 2008.

LEMOS, F. O.; CAMPAGNOLO, R.; MÜLLER, C. J. Desenvolvimento de cenários futuros integrados a previsão de demanda para auxílio no planejamento estratégico, tático e operacional de empresas. In: SIMPÓSIO DE ENGENHARIA DE PRODUÇÃO, 15., 2008, Bauru. Anais... Bauru: SIMPEP, 2008.

LIMA, F. G.; ALMEIDA, F. C. Previsão de séries temporais financeiras com o uso das Wavelets. In: ASSOCIAÇÃO NACIONAL DE PÓS-GRADUAÇÃO E PESQUISA EM ADMINISTRAÇÃO, 28., 2004, Curitiba. Anais... Curitiba: EnANPAD, 2004.

MENG, K.; DONG, Z. Y.; WONG, K. P. Self-adaptive radial basis function neural network for short-term electricity price forecasting. IET Generation. Transmission. Distribution, v. 3, n. 4, p. 325-335, 2009.
NOVAES, A. G. Logística e gerenciamento da cadeia de distribuição: estratégia, operação e avaliação. Rio de Janeiro: Elsevier, 2007.

SILVA, I. N.; SPATTI, D. H.; FALUZINO, R. A. Redes neurais artificiais: para engenharias e ciências aplicadas. São Paulo: Artliber, 2010.

VASCONCELLOS, L. H. R.; SAMPAIO, M.; PASTORE, R. Logística de varejo: uma análise sobre a questão da ruptura de estoque e suas causas no setor supermercadista paulista sob a ótica dos gestores do negócio. São Paulo: Núcleo de Pesquisa e Publicação - Escola Superior de Propaganda e Marketing. 2007.

WANKE, P. F. O impacto das características do negócio nas decisões logísticas e na organização do fluxo de produto: um estudo exploratório em seis setores econômicos. Revista de Administração Contemporânea, v. 7, n. 3, p. 163180, 2003.

Recebido: 26/09/2011

Received: 09/26/2011

Aprovado: $11 / 10 / 2011$

Approved: 10/11/2011 